\title{
Prevalence of Methicillin Resistant Staphylococcus aureus in Raw Goat Milks from Selected Farms in Terengganu, Malaysia
}

\author{
M. H. Chai ${ }^{a}$, T. A. M. Faiq ${ }^{a}$, S. M. Z. Ariffin ${ }^{b}$, Z. Suhailia, M. Z. Sukimana , \& M. F. Ghazalia,* \\ ${ }^{a}$ School of Animal Science, Faculty of Bioresources and Food Industry, Universiti Sultan Zainal Abidin, \\ Besut Campus, 22200, Besut, Terengganu, Malaysia \\ bDepartment of Veterinary Pre-Clinical Sciences, Faculty of Veterinary Medicine, Universiti Putra Malaysia, \\ 43400, Serdang, Selangor, Malaysia \\ Corresponding author: faizalghazali@unisza.edu.my \\ (Received 28-08-2019; Revised 07-11-2019; Accepted 11-11-2019)
}

\begin{abstract}
The emergence of antimicrobial drug resistant bacteria has been a concern worldwide. One of bacteria that has been reported to develop resistance is Methicillin Resistant Staphylococcus aureus (MRSA). Recent studies showed that Livestock Associated MRSA (LA-MRSA) was found in domestic food animals and their handlers. The aim of this study was to investigate the prevalence of MRSA in goat milk of goat farms located in Terengganu. A total of 664 udder milks were taken from 332 goats at 40 selected farms within Terengganu state. Then, screening of bacteria and isolation of suspected $S$. aureus isolates in the milk samples was done using selective agar, Gram staining and biochemical tests. The identity of the bacteria isolated was further confirmed using PCR where specific designed primers were used to detect the presence of $n u c$ gene of $S$. aureus (278bp) and $m e c A$ gene (533bp) of MRSA. Both $S$. aureus and MRSA isolates were also tested for their susceptibilities toward the antimicrobial drugs. Fifty milk samples were found to contain $S$. aureus and one of the $S$. aureus isolates were MRSA. The bacteria isolates were found to have higher tendency to be resistance toward Penicillin (26.0\%) and Oxacillin (12.0\%). This study provides useful data on the current status of MRSA prevalence in small ruminant's milk, which can be used to prevent transmission of LAMRSA to human and other animals.
\end{abstract}

Keywords: goat milk; antibiotic susceptibility; MRSA; nuc gene and mecA gene

\section{INTRODUCTION}

Recently, the emergence of antimicrobial resistant bacteria has been a concern worldwide and one of the bacteria that has been well known to develop resistance toward antibiotics is Methicillin Resistant Staphylococcus aureus (MRSA). In animals, MRSA also causes an array of infections in economically important livestock animals (Fitzgerald, 2012). Treatment of MRSA infection can be difficult due to the ability of the bacteria to inhibit the reaction of antibiotics, thus limiting the effectiveness of antibiotic treatment. It was found that MRSA is capable of making a penicillin binding protein (PBP2a) which is encoded by the mecA gene (Cuny et al., 2015). The PBP2a prevents beta-lactam antibiotics from binding to the cell wall protein and thus mediate the inhibitory effect of those antibiotics (Cuny et al., 2015).

MRSA was first found in 1961 after methicillin was introduced (Chamber \& DeLeo, 2009). In the late 1990s, new MRSA clones emerged in the community, where healthy individuals without history of hospitalization had been found to carry this strain (Guardabassi et al., 2013). Then, MRSA was found to be present in livestock animals. In the early 21st century, a livestock associ- ated MRSA strain with a sequence type 398 (ST398) was first found in pig, which suggested the emergence of Livestock Associated MRSA (LA-MRSA). Recent studies have shown that LA-MRSA was frequently found in various livestock and food animal products around the globe (Lozano et al., 2016; Tegegne et al., 2017). In early studies, the antimicrobial resistance and genetic background of MRSA were thought to be different according to their specific hosts. However, this perspective changed when MRSA from different sources were found to have low host specificity and similar genomic sequence (Cuny et al., 2015). Hence, this suggests that MRSA can be transmitted across species, such as from animal to human and vice versa. This raise health and food hygiene concerns as LA-MRSAs that present in live animals and their products, such as raw milk, egg and meat are capable of transmitting, colonizing and infecting the human.

In Malaysia, MRSA isolates were found in pigs. A study conducted by Neela et al. (2009) reported that 10 $(1.96 \%)$ LA-MRSA (ST9 and ST1) were isolated from pigs in 9 different pig farms, showing that LA-MRSA already present in Malaysian farming industry. However, the data on the prevalence of $S$. aureus and MRSA in 
raw milk as well their antibiotic resistance profiles in Malaysian goat are still limited. As MRSA had been successfully isolated from both healthy and mastitis milk in dairy animals around the globe (Holmes \& Zadoks, 2011; Nam et al., 2011; Gopal et al., 2017; Tegegne et al., 2017), it is a possibility that MRSA may present among dairy goats in Malaysia. This study aims to study the prevalence of MRSA in Terengganu's raw goat milks (subclinical and clinical mastitis as well healthy milks) and the antibiotic resistance profile of $S$. aureus isolates. The prevalence data in this study will provide information that help to prevent further transmission of MRSA to the other animal farms and human community as well as raise the awareness of applying good farm biosecurity practices. Besides, the antibiotic resistance profile will help the Terengganu farmers and veterinary officers to have a better understanding on the current AMR status in goat and provides insight on the kind of drugs that can be used to treat $S$. aureus infection, particularly mastitis in goats.

\section{MATERIALS AND METHODS}

\section{Milk Samples Collection}

A total of 664 udder (both left and right sides) raw milk samples from 332 lactating goats were collected at 40 small ruminant farms located in Terengganu, Peninsular Malaysia. The sample size was determined using GraphPad StatMate $\bigodot$ software for cross sectional and random sampling. A 5\% absolute precision and $95 \%$ level of confidence was used for determining the sample size. An expected prevalence of $30 \%$ was used to determine the maximum sample size. The prevalence of MRSA was determined as the percentage (\%) of raw milk samples which positive for mecA gene. The milk was collected using a sterile hand milking method and approximately $10 \mathrm{~mL}$ of milk sample was collected in a sterile falcon tube. The subclinical mastitis was pre-examined by Californian Mastitis Test (CMT) and clinical mastitis was determined based on the clinical signs such as udder pain, swelling, redness, warmth and gross changes in the milk. The samples were stored in a cooler box with approximately at $4^{\circ} \mathrm{C}$ and transported from the sampling sites to the Microbiology Laboratory, Universiti Sultan Zainal Abidin, Besut Campus within one day period for further analysis.

\section{Phenotypic Identification of S. aureus}

A $10 \mu \mathrm{L}$ of milk samples were plated on Mannitol Salt agar (Sigma-Aldrich, USA) and incubated at $37^{\circ} \mathrm{C}$ up to 48 hours. The appearance of the bacterial colonies was observed and recorded on 24 and 48 hours. Yellow bacterial colonies with yellow zones on the Mannitol Salt Agar were picked and cultured on the Nutrient Agar supplemented with $7.5 \%$ of Sodium chloride. The suspected bacterial colonies were further examined using Gram staining and biochemical tests (haemolysis test, catalase test, oxidase test and coagulase test). Bacterial isolates that were gram positive, cocci shaped and showed biochemical characteristics identical to $S$. aureus were kept and cultured on the enrichment agar for further testing.

\section{Genotypic Identification of S. aureus and MRSA}

Genotypic identification of $S$. aureus and MRSA started with DNA extraction of suspected S. aureus described by Suhaili et al. (2018). DNA amplification was then performed using two different sets of primers to detect the presence of nuc gene in S. aureus and mecA gene in MRSA (Suhaili et al., 2018). Amplification products were separated using gel based electrophoresis in a $2.0 \%(\mathrm{w} / \mathrm{v})$ agarose gel (Promega, USA) in a 1X tris-borate-EDTA (TBE) running buffer (Bioline, UK). The gels were visualized and using Fujifilm LAS-4000 gel documentation system. Bacteria isolates showing DNA bands at the size of $278 \mathrm{bp}$ (nuc gene) and $533 \mathrm{bp}$ (mecA gene) were considered as $S$. aureus and MRSA respectively.

\section{Antibiotic Susceptibility Tests}

The antibiotic susceptibility tests were conducted according to the Clinical and Laboratory Standards Institute (CLSI) guidelines. Antibiotic discs were placed on Muller Hinton Agar plates inoculated with 0.5 McFarland Standardized cultures. Three duplicates were done for each isolate. The plates were then incubated at $35^{\circ} \mathrm{C}$ for $18-24$ hours. The diameter of the inhibition zones were measured and compared to the CLSI Disc Diffusion breakpoints (CLSI, 2018).

\section{RESULTS}

\section{Prevalence of MRSA in Raw Goat Milks}

Out of 664 milk samples, 50 (7.5\%) were from clinical mastitis and $67(10.1 \%)$ were from subclinical mastitis animals (Table 1). Bacteriological examination revealed that $198 / 664(29.8 \%)$ of raw milk samples were positive for $S$. aureus. Out of the 198 presumptive S. aureus, $50(25.3 \%)$ isolates were found to carry nuc gene (Figure 1) that unique to $S$. aureus. All of the 50 isolates that contained nuc gene were later tested using gel-based PCR to investigate the presence of mec $A$ gene.

Table 1. Number of samples and the results of bacteriological examination and PCR assay

\begin{tabular}{lcccc}
\hline \multicolumn{1}{c}{ Mastitis status } & No. of samples & $\begin{array}{c}\text { No. of samples positive for } \\
\text { S. aureus isolation }\end{array}$ & $\begin{array}{c}\text { No. of samples positive } \\
\text { for nuc gene }\end{array}$ & $\begin{array}{c}\text { No. of samples positive } \\
\text { for mecA gene }\end{array}$ \\
\hline Clinical mastitis & 50 & 18 & 10 & 11 \\
Subclinical mastitis & 67 & 25 & 0 & 29 \\
No mastitis & 547 & 155 & 1 \\
\hline
\end{tabular}


One $(1 / 50 ; 2 \%)$ of the $S$. aureus isolate from normal milk sample was found to carry mecA gene (Figure 2) and thus this isolate is considered to be MRSA.

\section{Antibiotic Susceptibility Profiles}

Antibiotic susceptibility profiles of the isolated $S$. aureus are shown in Table 2. Of the 50 S. aureus isolates, $26 \%(13 / 50)$ were resistant to penicillin and $10 \%(5 / 50)$ were resistant to oxacillin, respectively. In addition, about $6 \%(3 / 50)$ of the $S$. aureus were resistant to tetracycline. Of a total of 50 isolates of $S$. aureus, $74 \%(37 / 50)$ showed full susceptibility to vancomycin, cefotaxime, doxycycline, amikacin, norfloxacin, clindamycin, kanamycin, cephalothin and chloramphenicol. The MRSA isolate showed a similar antibiotic susceptibility pattern as the S. aureus isolates (Table 2).

\section{DISCUSSION}

Recently, livestock-associated MRSA (LA-MRSA) has become an emerging problem in the field of veterinary medicine due to their multiple antibiotic resistance characteristics. The livestock-associated MRSA (LAMRSA) was first isolated from a dairy cow with mastitis (Fitzgerald, 2012). Later on, MRSA has been reported globally in cattle, pigs, horses and poultry (Petersen et al., 2013).

In the present study, the prevalence of MRSA in raw goat milks was $2 \%(1 / 50)$. This result was lower than that of Tegegne et al. (2017) who recorded $25.7 \%$ (9/35) prevalence rates of MRSA in raw goat milk. Previous study by Aras et al. (2012) reported MRSA was found in caprine mastitis only with a low prevalence (4.8\%; 2/42). Meanwhile, study conducted by Virdis et al. (2010) reported none of the $S$. aureus isolates obtained were MRSA. MecA gene encodes for the penicillin binding protein (PBP-2a) which allows the bacteria to be resistance towards beta-lactam antibiotics. This chromosomally derived gene can be frequently found in MRSA but absent in methicillin susceptible Staphylococci isolates. Detection of mecA gene using PCR amplification technique is considered to be a reliable method to identify MRSA (Tsubakishita et al., 2010; Bastidas et al., 2019).

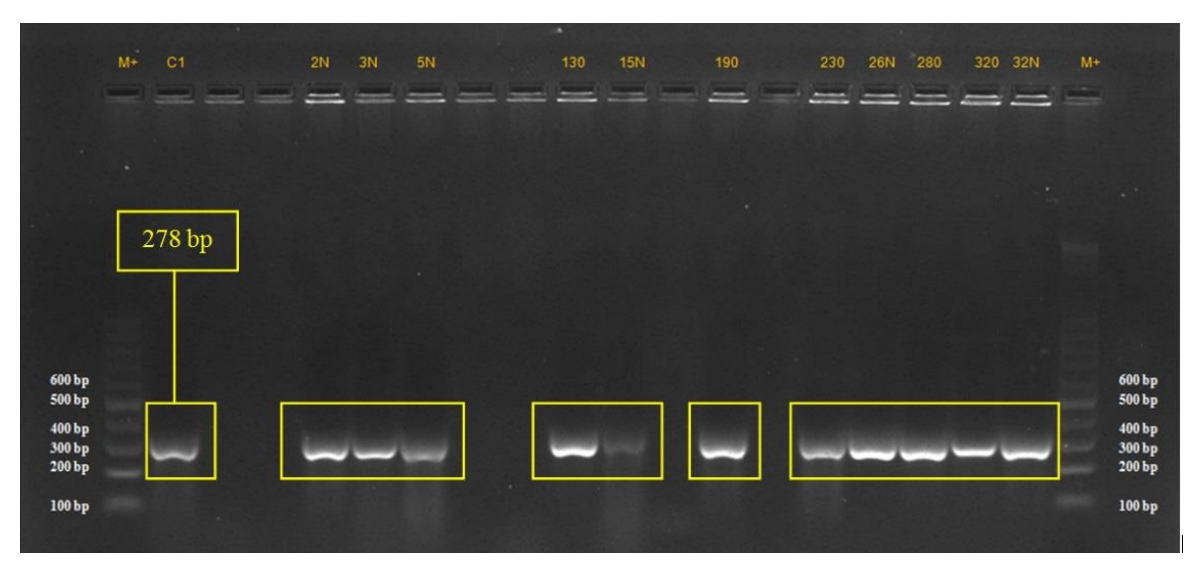

Figure 1. Agarose gel electrophoresis image of the $n u c$ gene $(278 \mathrm{bp})$ from representative isolates (lane $2 \mathrm{~N}, 3 \mathrm{~N}, 5 \mathrm{~N}, 130,15 \mathrm{~N}, 190,230,26 \mathrm{~N}, 280,320 \& 32 \mathrm{~N}$ ); lane $\mathrm{C} 1$ is a positive control (ATCC 700699) and lane M+ is a 1000 bp ladder.

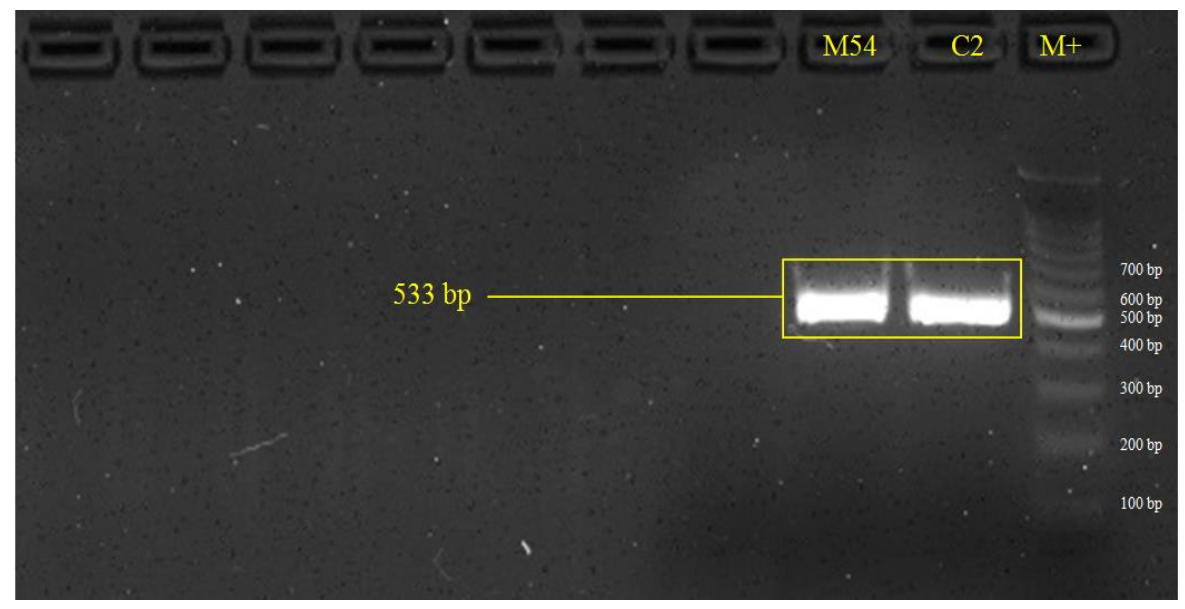

Figure 2. Agarose gel electrophoresis image of the mecA gene (533 bp) from representative isolates lane; lane C2 is a positive control (ATCC 700699) and lane M+ is a 1000 bp ladder. 
Table 2. Antibiotic susceptibility profiles of S. aureus and MRSA isolates

\begin{tabular}{|c|c|c|c|c|c|c|}
\hline \multirow{2}{*}{ Isolates } & \multirow{2}{*}{ Antimicrobials } & \multirow{2}{*}{ Symbol } & \multirow{2}{*}{$\begin{array}{c}\text { Disk potency } \\
(\mu g)\end{array}$} & \multicolumn{3}{|c|}{ Number of isolates (\%) } \\
\hline & & & & Resistant & Intermediate & Sensitive \\
\hline \multirow[t]{14}{*}{ S. aureus } & Penicillin & $\mathrm{P}$ & 10 & $13(26)$ & $0(0)$ & $37(74)$ \\
\hline & Oxacillin & OX & 1 & $6(12)$ & $0(0)$ & $44(88)$ \\
\hline & Tetracycline & $\mathrm{TE}$ & 30 & $3(6)$ & $1(2)$ & $46(92)$ \\
\hline & Amoxycillin & AMC & 10 & $2(4)$ & $0(0)$ & $48(96)$ \\
\hline & Cefoxitin & FOX & 30 & $1(2)$ & $0(0)$ & $49(98)$ \\
\hline & Vancomycin & VA & 30 & $0(0)$ & $0(0)$ & $50(100)$ \\
\hline & Cefotaxime & CTX & 30 & $0(0)$ & $0(0)$ & $50(100)$ \\
\hline & Doxycycline & DO & 30 & $0(0)$ & $0(0)$ & $50(100)$ \\
\hline & Amikacin & AK & 30 & $0(0)$ & $0(0)$ & $50(100)$ \\
\hline & Norfloxacin & NOR & 10 & $0(0)$ & $0(0)$ & $50(100)$ \\
\hline & Clindamycin & DA & 2 & $0(0)$ & $0(0)$ & $50(100)$ \\
\hline & Kanamycin & K & 30 & $0(0)$ & $0(0)$ & $50(100)$ \\
\hline & Cephalothin & KF & 30 & $0(0)$ & $0(0)$ & $50(100)$ \\
\hline & Chloramphenicol & $\mathrm{C}$ & 30 & $0(0)$ & $0(0)$ & $50(100)$ \\
\hline \multirow[t]{13}{*}{ MRSA } & Penicillin & $\mathrm{P}$ & 10 & $1(100)$ & $0(0)$ & $0(0)$ \\
\hline & Oxacillin & OX & 1 & $1(100)$ & $0(0)$ & $0(0)$ \\
\hline & Tetracycline & TE & 30 & $1(100)$ & $0(0)$ & $0(0)$ \\
\hline & Amoxycillin & $\mathrm{AMC}$ & 10 & $0(0)$ & $0(0)$ & $1(100)$ \\
\hline & Cefoxitin & FOX & 30 & $0(0)$ & $0(0)$ & $1(100)$ \\
\hline & Vancomycin & VA & 30 & $0(0)$ & $0(0)$ & $1(100)$ \\
\hline & Cefotaxime & CTX & 30 & $0(0)$ & $0(0)$ & $1(100)$ \\
\hline & Doxycycline & $\mathrm{DO}$ & 30 & $0(0)$ & $0(0)$ & $1(100)$ \\
\hline & Amikacin & $\mathrm{AK}$ & 30 & $0(0)$ & $0(0)$ & $1(100)$ \\
\hline & Norfloxacin & NOR & 10 & $0(0)$ & $0(0)$ & $1(100)$ \\
\hline & Clindamycin & DA & 2 & $0(0)$ & $0(0)$ & $1(100)$ \\
\hline & Kanamycin & K & 30 & $0(0)$ & $0(0)$ & $1(100)$ \\
\hline & Cephalothin & KF & 30 & $0(0)$ & $0(0)$ & $1(100)$ \\
\hline
\end{tabular}

Apart from mecA gene, amplification of nuc gene is important in order to study the prevalence of $S$. aureus in individual goat milks in Terengganu. Many researches had indicated that detection of S. aureus by using PCR amplification of nuc gene has a great potential to be used for rapid diagnosis of $S$. aureus (Gao et al., 2011; Kateete et al., 2010; Banada, et al., 2012). In the present study, 50 isolates were confirmed of carrying nuc gene (Figure 1), indicating the presence of $S$. aureus in single individual raw goat milk. The number of confirmed S. aureus isolates through PCR is lower than that of confirmed by phenotypic screening methods. This is not surprising, as these phenotypic screening methods often lead to ambiguous results due to the large amount of field isolates, inconsistent test performances and different biochemical characteristics of bacteria isolates that differ from the patterns of a known genus and species (Kateete et al., 2010). The present study showed a slightly higher $S$. aureus prevalence rate $(25.3 \%)$ compared with Qian et al. (2019) who recorded the prevalence rate of $23.5 \%(68 / 289)$. It is important to note that the presence of $S$. aureus in raw goat milks as the bacteria are often related to Staphylococcal food poisoning and raise public health concern among raw milk consumer (Qian et al., 2019).

In this study, the $S$. aureus isolates showed different degrees of resistances toward various antibiotics. $S$. aureus isolates were found to have higher tendency to be resistance toward beta-lactams antibiotics such as oxacillin $(12.0 \%)$ and penicillin $(26.0 \%)$. This may due to the frequent usage of penicillin related drugs for mastitis treatment by the local farmers. However, the percentages of antibiotic resistance to penicillin were still low compared to the previous studies conducted by Ganai et al. (2016) and Massawe et al. (2019) that reported the resistance rates at $76.47 \%$ and $57.2 \%$ respectively. Resistance towards beta-lactams sensitive antibiotics and related antibiotics among $S$. aureus is frequently observed and may be aids by defensive mechanisms that existed within the $S$. aureus population. Since Staphylococci are capable of expressing the penicillinbinding protein 2a (PBP 2a), it can be speculated that the $S$. aureus isolated produce the defensive enzyme to protect themselves from beta-lactam related antibiotics.

In the present study, 3/50 of the $S$. aureus isolates were resistant to tetracycline. The findings of this study are consistent with previous study by Rubin et al. (2011) reported that $S$. aureus isolated from various animals showed resistance towards tetracycline. In another study conducted by Massawe et al. (2019) reported 19\% of $S$. aureus isolates were found to be resistant towards tetracycline. According to Foster (2017), the presence of Tet efflux pumps (TetA(K) and TetA(L)) and TetO/M determinants within the Staphylococci assists the sur- 
vival of Staphylococci towards tetracycline. The present study showed only a low number of $S$. aureus isolates were resistance to amoxicillin $(2 / 48 ; 4 \%)$ and cefoxitin $(1 / 49 ; 2 \%)$. However, our study showed $100 \%$ sensitivity toward vancomycin, cefotaxime, doxycycline, amikacin, norfloxacin, clindamycin, kanamycin, cephalothin and chloramphenicol in $S$. aureus isolates, implying those antibiotics can be used to treat $S$. aureus-related subclinical and clinical mastitis infection of goats in Terengganu.

In general, the antibiotic resistance profile of $S$. aureus in this study is almost similar to that reported by Suhaili et al. (2018) where most of $S$. aureus isolates from human in Malaysia are susceptible to most of antibiotics, with the exception of penicillin $(49 / 49 ; 100 \%)$ erythromycin $(8 / 49 ; 16 \%)$, cefoxitin $(4 / 49 ; 8 \%)$, oxacillin $(4 / 49$; $8 \%)$ and clindamycin $(2 / 49 ; 4 \%)$. However, the resistance rates of $S$. aureus towards antibiotic in the present study are lower when compared to a similar study carried by Qian et al. (2019). Qian et al. (2019) reported 97.06\% $(66 / 68)$ S. aureus from raw goat milk in China have resistance at least towards one tested antibiotics where the isolates showed resistance towards important antibiotics such as penicillin $(79.41 \%, 54 / 68)$, oxacillin $(60.29 \%$, $41 / 68)$ piperacillin $(41.18 \%, 28 / 68)$, trimethoprimsulfamethoxazole $(33.82 \%, 23 / 68)$, ciprofloxacin $(29.41 \%$, $20 / 68)$, gentamicin $(27.94 \%, 19 / 68)$, clindamycin $(20.59 \%$, $14 / 68)$, cefazolin $(19.12 \%, 13 / 68)$ and linezolid $(14.71 \%$, $10 / 68)$. Besides, S. aureus isolated from caprine mastitis were found to be resistance toward kanamycin (7/22; $28 \%)$, oxytetracycline $(4 / 22 ; 16 \%)$ and ampicillin $(3 / 22$; $12 \%$ ) (Virdis et al., 2010).

\section{CONCLUSION}

This study demonstrates that the presence of MRSA $(2 \% ; 1 / 50)$ and S. aureus $(25.3 \% 50 / 198)$ in raw goat milks in Terengganu. The isolated $S$. aureus showed resistances towards penicillin, oxacillin, tetracyclines, amoxycillin and cefoxitin, suggesting the emergence of antibiotic resistance in goat's milk. Therefore, continued efforts of antimicrobial stewardship programme are needed to promote good hygiene practices and responsible usage of antimicrobials in goat farms in Terengganu, Malaysia.

\section{CONFLICT OF INTEREST}

None of the authors have any potential conflict of interest to declare.

\section{ACKNOWLEDGEMENT}

The authors thank the Research Acculturation Grant Scheme (RAGS) (Project code: RAGS/1/2015/SG0/ UNISZA/02/1) for funding this study. Special thanks to the Department of Veterinary Services, Terengganu, Malaysia.

\section{REFERENCES}

Aras, Z., L. Aydin, \& K. Kav. 2012. Isolation of methicillin-resistant Staphylococcus aureus from caprine mastitis cases. Small Rumin. Res. 102: 68-73. https://doi.org/10.1016/j. smallrumres.2011.08.014

Banada, P. P., S. Chakravorty, D. Shah, M. Burday, F. M. Mazzella, \& D. Alland. 2012. Highly sensitive detection of Staphylococcus aureus directly from patient blood. PLoS ONE 7(2): e31126. https://doi.org/10.1371/journal. pone.0031126

Bastidas, C.A., I. Villacrés-Granda, D. Navarrete, M. Monsalve, M. Coral-Almeida, \& S. G. Cifuentes. 2019. Antibiotic susceptibility profile and prevalence of mecA and lukS-PV/lukF-PV genes in Staphylococcus aureus isolated from nasal and pharyngeal sources of medical students in Ecuador. Infect. Drug Resist. 12: 2553. https://doi.org/10.2147/IDR.S219358

Chambers, H. F. \& F. R. DeLeo. 2009. Waves of resistance: Staphylococcus aureus in the antibiotic era. Nat. Rev. Microbiol. 7:629. https://doi.org/10.1038/nrmicro2200

Chu, C., C. Yu, Y. Lee, \& Y. Su. 2012. Genetically divergent methicillin-resistant Staphylococcus aureus and sec-dependent mastitis of dairy goats in Taiwan. BMC Vet. Res. 8: 39. https://doi.org/10.1186/1746-6148-8-39

Clinical and Laboratory Standards Institute. 2018. Performance Standards for Antimicrobial Susceptibility Testing. 28th ed. CLSI supplement M100. Wayne, PA: CLSI.

Cuny, C., L.H. Wieler, \& W. Witte. 2015. Livestock-Associated MRSA: The impact on humans. Antibiotics 4:521-543. https://doi.org/10.3390/antibiotics4040521

Fitzgerald, J. R. 2012. Livestock-associated Staphylococcus aureus: origin, evolution and public health threat. Trends Microbiol. 20:192-198. https://doi.org/10.1016/j. tim.2012.01.006

Foster, T. J. 2017. Antibiotic resistance in Staphylococcus aureus. Current status and future prospects. FEMS Microbiol. Rev. 41: 430-449. https://doi.org/10.1093/femsre/fux007

Ganai, A. W., S. K. Kotwal, N. A. J. I. M. A. A. N. A. Wani, M. A. Malik, R. I. Z. W. A. N. Jeelani, S. Kour, \& R. Zargar. 2016. Detection of mecA gene of methicillin resistant Staphylococcus aureus by PCR assay from raw milk. Indian J. Anim. Sci. 86: 508-511.

Gao, J., M. Ferreri, X.Q. Liu, L.B. Chen, J. L. Su, \& B. Han. 2011. Development of multiplex polymerase chain reaction assay for rapid detection of Staphylococcus aureus and selected antibiotic resistance genes in bovine mastitic milk samples. J. Vet. Diagn. Invest. 23:894-901. https://doi. org/10.1177/1040638711416964

Gopal, S. \& K. C. Divya. 2017. Can methicillin-resistant Staphylococcus aureus prevalence from dairy cows in India act as potential risk for community-associated infections?: A review., Vet. World 10: 311. https://doi. org/10.14202/vetworld.2017.311-318

Guardabassi, L., J. Larsen, J. S. Weese, P. Butaye, A. Battisti, J. Kluytmans, D. H. Lloyd, \& R. L. Skov. 2013. Public health impact and antimicrobial selection of meticillin-resistant staphylococci in animals. J. Glob. Antimicrob. Resist. 1:5562. https://doi.org/10.1016/j.jgar.2013.03.011

Holmes, M.A. \& R. N. Zadoks. 2011. Methicillin resistant S. aureus in human and bovine mastitis. J. Mammary Gland Biol. Neoplasia. 16:373-382. https://doi.org/10.1007/ s10911-011-9237-x

Kateete, D. P., C. N. Kimani, F. A. Katabazi, A. Okeng, M. S. Okee, A. Nanteza, M. L. Joloba, \& F. C. Najjuka. 2010. Identification of Staphylococcus aureus: DNase and Mannitol salt agar improve the efficiency of the tube coagulase test. Ann. Clin. Microbiol. Antimicrob. 9: 23. https:// doi.org/10.1186/1476-0711-9-23

Lozano, C., H. Gharsa, K. Ben Slama, M. Zarazaga, \& C. Torres. 2016. Staphylococcus aureus in animals and food: methicillin resistance, prevalence and population Structure. A review in the African continent. Microorganisms 4:12. https://doi.org/10.3390/microorganisms4010012 
Massawe, H. F., R. H. Mdegela, \& L. R. Kurwijila. 2019. Antibiotic resistance of Staphylococcus aureus isolates from milk produced by smallholder dairy farmers in Mbeya Region, Tanzania. Int. J. One Health 5:31-37. https:// doi.org/10.14202/IJOH.2019.31-37

Nam, H.M., A. L. Lee, S. C. Jung, M. N. Kim, G. C. Jang, S. H. Wee, \& S. K. Lim. 2011. Antimicrobial susceptibility of Staphylococcus aureus and characterization of methicillinresistant Staphylococcus aureus isolated from bovine mastitis in Korea. Foodborne Pathog. Dis. 8: 231-238. https:// doi.org/10.1089/fpd.2010.0661

Neela, V., A. M. Zafrul, N. S. Mariana, A. van Belkum, Y. K. Liew, \& E. G. Rad. 2009. Prevalence of ST9 methicillinresistant Staphylococcus aureus among pigs and pig handlers in Malaysia. J. Clin. Microbiol, 47: 4138-4140. https:// doi.org/10.1128/JCM.01363-09

Petersen, A., M. Stegger, O. Heltberg, J. Christensen, A. Zeuthen, L. K. Knudsen, T. Urth, M. Sorum, L. Schouls, J. Larsen, \& R. Skov. 2013. Epidemiology of methicillinresistant Staphylococcus aureus carrying the novel mecC gene in Denmark corroborates a zoonotic reservoir with transmission to humans. Clin. Microbiol. Infect. 19: E16-E22. https://doi.org/10.1111/1469-0691.12036

Qian, W., L. Shen, X. Li, T. Wang, M. Liu, W. Wang, Y. Fu, \& Q. Zeng. 2019. Epidemiological Characteristics of Staphylococcus aureus in Raw Goat Milk in Shaanxi Province, China. Antibiotics 8:141. https://doi.org/10.3390/ antibiotics8030141
Rubin, J. E., K. R. Ball, \& M. Chirino-Trejo. 2011. Antimicrobial susceptibility of Staphylococcus aureus and Staphylococcus pseudintermedius isolated from various animals. Can. Vet. J. 52: 153.

Stastkova, Z., S. Karpiskova, \& R. Karpiskova. 2009. Occurrence of methicillin- resistant strains of Staphylococcus aureus at a goat breeding farm. Vet. Med. 54: 419-426. https://doi.org/10.17221/88/2009-VETMED

Suhaili, Z., N. M. A. Putri'Amira Rafee, C. C. Yeo, S. A. Nordin A. R. A. Rahim, M. M. J. Al-Obaidi, \& M. N. M. Desa. 2018. Characterization of resistance to selected antibiotics and Panton-Valentine leukocidin-positive Staphylococcus aureus in a healthy student population at a Malaysian University. Germs 8: 21. https://doi.org/10.18683/ germs.2018.1129

Tegegne, H.A., I. Koláčková, \& R. Karpíšková. 2017. Diversity of livestock associated methicillin-resistant Staphylococcus aureus. Asian Pac. J. Trop. Med. 10: 929-931. https://doi.org/10.1016/j.apjtm.2017.08.013

Tsubakishita, S., K. Kuwahara-Arai, T. Baba, \& K. Hiramatsu. 2010. Staphylococcal cassette chromosome mec-like element in Macrococcus caseolyticus. Antimicrob. Agents Chemother. 54:1469-1475. https://doi.org/10.1128/ AAC.00575-09

Virdis, S., C. Scarano, F. Cossu, V. Spanu, C. Spanu, \& E. P. L. De Santis. 2010. Antibiotic resistance in Staphylococcus aureus and coagulase negative staphylococci isolated from goats with subclinical mastitis. Vet. Med. Int. vol. 2010 https://doi.org/10.4061/2010/517060 